\title{
Prognostic Value of Apparent Diffusion Coefficient in Oropharyngeal Carcinoma
}

\author{
Heli J. Sistonen ${ }^{1} \cdot$ Katri Aro $^{2} \cdot$ Timo Atula $^{2}$ (D) Lauri Jouhi $^{2} \cdot$ Riikka Lindén $^{1} \cdot$ Laura Tapiovaara $^{2}$ (D) $\cdot$ Venla Loimu $^{3}$. \\ Antti Markkola'
}

Received: 20 November 2020 / Accepted: 22 March 2021 / Published online: 20 April 2021

(C) The Author(s) 2021

\begin{abstract}
Purpose To investigate clinical and radiological factors predicting worse outcome after (chemo)radiotherapy ([C]RT) in oropharyngeal squamous cell carcinoma (OPSCC) with a focus on apparent diffusion coefficient (ADC).

Methods This retrospective study included 67 OPSCC patients, treated with (C)RT with curative intent and diagnosed during 2013-2017. Human papilloma virus (HPV) association was detected with p16 immunohistochemistry. Of all 67 tumors, 55 were p16 positive, 9 were p16 negative, and in 3 the p16 status was unknown. Median follow-up time was 38 months. We analyzed pretreatment magnetic resonance imaging (MRI) for factors predicting disease-free survival (DFS) and locoregional recurrence (LRR), including primary tumor volume and the largest metastasis. Crude and p16-adjusted hazard ratios were analyzed using Cox proportional hazards model. Interobserver agreement was evaluated.

Results Disease recurred in 13 (19.4\%) patients. High ADC predicted poor DFS, but not when the analysis was adjusted for p16. A break in RT (hazard ratio, $\mathrm{HR}=3.972,95 \%$ confidence interval, CI 1.445-10.917, $p=0.007$ ) and larger metastasis volume $(\mathrm{HR}=1.041,95 \%$ CI $1.007-1.077, p=0.019)$ were associated with worse DFS. A primary tumor larger than $7 \mathrm{~cm}^{3}$ was associated with increased LRR rate $(\mathrm{HR}=4.861,1.042-22.667, p=0.044)$. Among p16-positive tumors, mean ADC was lower in grade 3 tumors compared to lower grade tumors $(0.736$ vs. $0.883 ; p=0.003)$.

Conclusion Low tumor ADC seems to be related to p16 positivity and therefore should not be used independently to evaluate disease prognosis or to choose patients for treatment deintensification.
\end{abstract}

Keywords Human papilloma virus · Magnetic resonance imaging $\cdot$ Diffusion weighted imaging $\cdot$ Radiotherapy $\cdot$ Tumor volume

\section{Introduction}

Oropharyngeal squamous cell carcinoma (OPSCC) subdivides into human papilloma virus (HPV)-associated and non-HPV-associated cancer groups. Immunohistochemical (IHC) overexpression of p16 is a surrogate marker for HPV and used in the current TNM classification [1] and the World Health Organization (WHO) classification of head and neck tumors [2]. A HPV-associated OPSCC usually

All authors reviewed the final version of the manuscript and gave their consent for publication.

Availability of data and material Inquiries to the corresponding author.

Code availability Not applicable.

Heli J. Sistonen

heli.sistonen@hus.fi responds well to (chemo)radiation ([C]RT), and treatment deintensification trials are underway to reduce treatment adverse effects $[3,4]$. In a small subset of patients, however, the disease recurs making salvage surgery more demanding.

Prior to treatment, patients undergo multiplanar radiological imaging. Some radiological features show prognostic impact, such as volume of the primary tumor and metastasis, lymph node cystic or matted morphology, and extra-

1 Radiology, HUS Diagnostic Center, University of Helsinki and Helsinki University Hospital, Haartmaninkatu 4, 00029 HUS Helsinki, Finland

2 Department of Otorhinolaryngology-Head and Neck Surgery, University of Helsinki and Helsinki University Hospital, Kasarmikatu 11-13, 00029 HUS Helsinki, Finland

3 Department of Oncology, University of Helsinki and Helsinki University Hospital, Paciuksenkatu 3, 00029 HUS Helsinki, Finland 
nodal extension (ENE) [5-8]. Many reports link primary tumor relatively high apparent diffusion coefficient (ADC) in magnetic resonance imaging (MRI) with lower radiosensitivity [7, 9-16], although some conflicting evidence has emerged [17-19]. These studies include cancers from multiple head and neck sites, however, and all but one overlook HPV association [17]. This confounds results because HPV positive tumors tend to have lower ADC [20-24], and respond better to (C)RT.

Our aim was to investigate the prognostic effect of clinical and radiological variables, including ADC, in pretreatment MRI in an OPSCC population treated with (C)RT with curative intent. These features were then compared with the tumor p16 status. We hypothesized that ADC would serve to estimate treatment response and prognosis after (C)RT and improve management guidelines. This might support the decision to exclude patients who seem to have a worse prognosis from the deintensification protocols, and lead to offering them more extensive treatment.

\section{Material and Methods}

\section{Study Design and Patient Selection}

We included OPSCC patients treated at the Helsinki University Hospital Head and Neck Center, diagnosed between January 2013 and December 2017. Our multidisciplinary tumor board reviewed the diagnostics, staging, and treatment plan for all patients. The follow-up data were collected in December 2018. Inclusion criteria were histologically proven OPSCC, available pretreatment diagnostic MRI, and (C)RT with curative intent. We excluded patients with previous head and neck cancer (HNC) or distant metastasis at presentation (Fig. 1). The final study cohort consisted of 67 patients, of whom 55 had p16 positive disease, 9 had p16 negative disease, and in 3 patients the result of p16 status was unavailable. We chose the years from 2013 onwards, when the diffusion-weighted imaging (DWI) sequence was added to our institute's tumor imaging protocol. The protocol remained mainly constant during the study period and DWI was available for 63 patients (for 52 of the 55 p16 positive patients).

\section{Treatment and Follow-up}

In a small subset of patients, the tumor was biopsied via tonsillectomy after MRI. We included 8 of these patients who had undergone a primary tonsillectomy with metastatic lymph nodes $(\mathrm{N}+$ disease), as these patients received the same locoregional treatment as others and they are a typical patient population receiving definitive (C)RT. Patients who underwent tonsillectomy and had no neck metastases

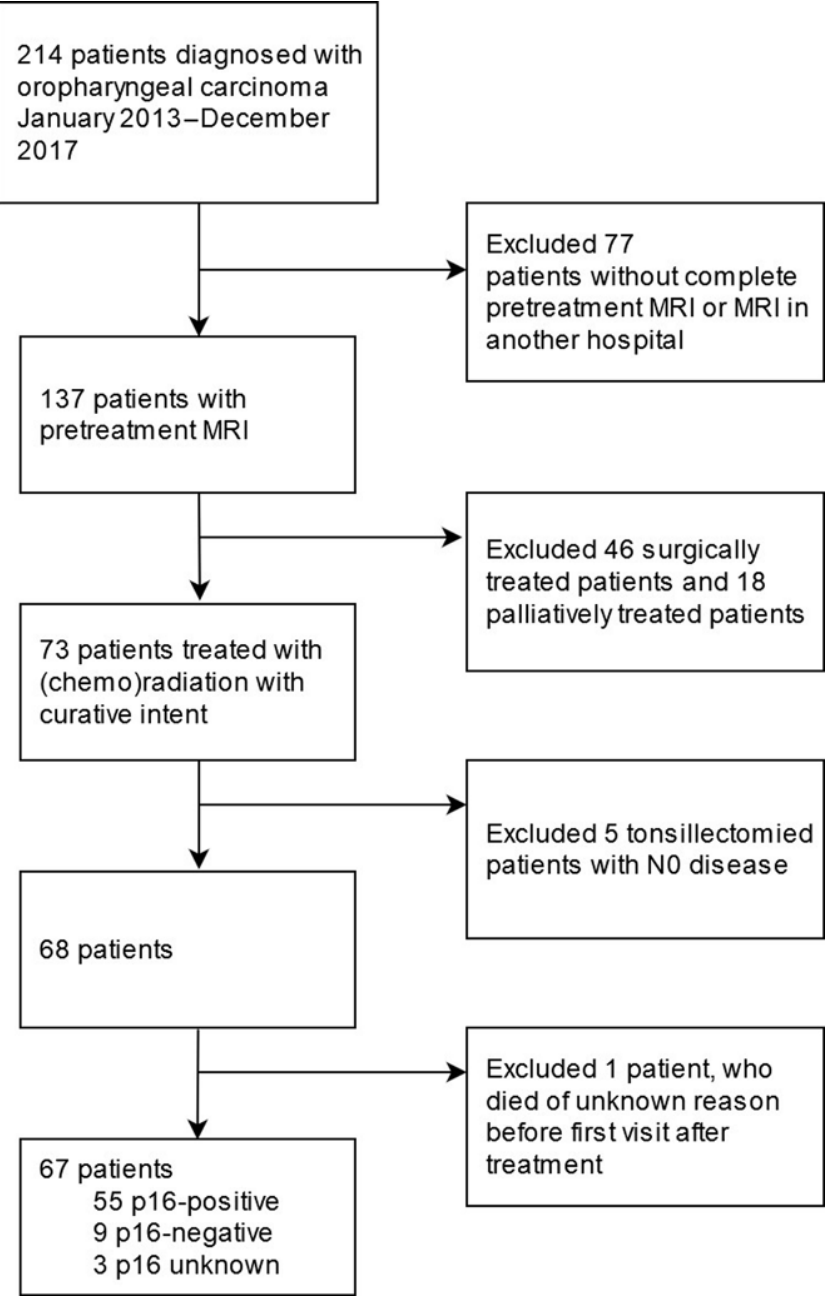

Fig. 1 Patient exclusion chart

(N0 disease) were excluded as they had no macroscopic tumor left prior to the RT. All patients were treated with intensity-modulated RT (IMRT), range 56-70 Gy; 66 patients received the treatment conventionally fractionated with $2 \mathrm{~Gy}$ daily fractions and 1 with simultaneous integrated boost (SIB). RT was delivered to the primary tumor and cervical lymph node areas. Chemotherapy was administered with weekly cisplatin $40 \mathrm{mg} / \mathrm{m}^{2}$ (maximum of 6 doses).

After treatment, patients underwent regular follow-up appointments and positron emission tomography with computed tomography (PET-CT) at 3 months. Additional diagnostic and therapeutic procedures were planned in cases of suspicion of a residual or recurrent disease. Locoregional recurrence (LRR) was defined either as a residual disease (a persistent disease in follow-up PET-CT and first clinical examination with no remission in between) or a later recurrent disease (a reappearance of the tumor at the primary site or metastases after a disease-free period). Biopsy or clear imaging evidence with progression confirmed the recurrence. Residual disease was found in 7 (10.4\%) and 
Table 1 Patient demographics, treatment data and treatment results, stratified by p16

\begin{tabular}{|c|c|c|c|c|}
\hline & $\begin{array}{l}\mathrm{p} 16+ \\
n=55\end{array}$ & $\begin{array}{l}\mathrm{p} 16- \\
n=9\end{array}$ & $\begin{array}{l}\text { All } \\
n=67\end{array}$ & $\begin{array}{l}\text { P-value } \\
\text { (p16+ vs. p16-) }\end{array}$ \\
\hline Age, years, mean (range) & $60.8(41-79)$ & $66.7(54-77)$ & $62(41-79)$ & 0.113 \\
\hline \multicolumn{5}{|l|}{ Gender, \% } \\
\hline Female & $9(16.4)$ & $7(77.8)$ & $14(20.9)$ & \multirow[t]{2}{*}{0.646} \\
\hline Male & $46(83.6)$ & $2(22.2)$ & $53(79.1)$ & \\
\hline \multicolumn{5}{|l|}{ Smoking, \% } \\
\hline No & $21(38.2)$ & $1(11.1)$ & $22(32.8)$ & \multirow[t]{4}{*}{0.001} \\
\hline Yes & $13(23.6)$ & $8(88.9)$ & $24(35.8)$ & \\
\hline Before & $20(36.4)$ & - & $20(29.9)$ & \\
\hline Data missing & $1(1.8)$ & - & $1(1.5)$ & \\
\hline \multicolumn{5}{|l|}{ Alcohol use, \% } \\
\hline No & $51(92.7)$ & $5(55.6)$ & $58(86.6)$ & \multirow[t]{3}{*}{0.012} \\
\hline Yes & $2(3.6)$ & $3(33.3)$ & $5(7.5)$ & \\
\hline Before & $2(3.6)$ & $1(11.1)$ & $4(6.0)$ & \\
\hline \multicolumn{5}{|l|}{ Tumor site, \% } \\
\hline Tonsils & $36(65.5)$ & $7(77.8)$ & $43(64.2)$ & \multirow[t]{3}{*}{0.154} \\
\hline Base of tongue & $18(32.7)$ & $1(11.1)$ & $21(31.3)$ & \\
\hline Posterior wall of the oropharynx & $1(1.8)$ & $1(11.1)$ & $3(4.5)$ & \\
\hline \multicolumn{5}{|l|}{ Grade, \% } \\
\hline 1 & - & - & $1(1.5)$ & \multirow[t]{4}{*}{$<0.001$} \\
\hline 2 & $7(12.7)$ & $7(77.8)$ & $15(22.4)$ & \\
\hline 3 & 45 (81.8) & $2(22.2)$ & 48 (71.6) & \\
\hline Data missing & $3(5.5)$ & - & $3(4.5)$ & \\
\hline \multicolumn{5}{|l|}{ T-stage (UICC8), \% } \\
\hline $\mathrm{T} 1$ & $12(21.8)$ & - & - & \multirow[t]{6}{*}{0.003} \\
\hline $\mathrm{T} 2$ & $27(49.1)$ & $2(22.2)$ & & \\
\hline $\mathrm{T} 3$ & $6(10.9)$ & $1(11.1)$ & & \\
\hline $\mathrm{T} 4$ & $10(18.2)$ & - & & \\
\hline $\mathrm{T} 4 \mathrm{a}$ & - & $5(55.6)$ & & \\
\hline $\mathrm{T} 4 \mathrm{~b}$ & - & $1(11.1)$ & & \\
\hline \multicolumn{5}{|l|}{$N$-stage (UICC8), \% } \\
\hline No & $6(10.9)$ & $3(33.3)$ & - & \multirow[t]{6}{*}{0.055} \\
\hline N1 & $43(78.2)$ & - & & \\
\hline $\mathrm{N} 2$ & $6(10.9)$ & - & & \\
\hline $\mathrm{N} 2 \mathrm{~b}$ & - & $1(11.1)$ & & \\
\hline $\mathrm{N} 2 \mathrm{c}$ & - & $2(22.2)$ & & \\
\hline $\mathrm{N} 3 \mathrm{~b}$ & - & $3(33.3)$ & & \\
\hline \multicolumn{5}{|l|}{ Stage, $\%$} \\
\hline I & $38(69.1)$ & - & - & \multirow[t]{6}{*}{$<0.001$} \\
\hline II & $7(12.7)$ & $2(22.2)$ & & \\
\hline III & $9(16.4)$ & $1(11.1)$ & & \\
\hline IV & $1(1.8)$ & - & & \\
\hline IVa & - & $3(33.3)$ & & \\
\hline $\mathrm{IVb}$ & - & $3(33.3)$ & & \\
\hline \multicolumn{5}{|l|}{ Treatment modality, $\%$} \\
\hline Chemoradiation & $50(90.9)$ & $8(88.9)$ & $61(91.0)$ & \multirow[t]{2}{*}{1.000} \\
\hline Radiation & $5(9.1)$ & $1(11.1)$ & $6(9.0)$ & \\
\hline $\begin{array}{l}\text { Time interval between diagnostic MRI and start of treatment, } \\
\text { days, mean, range }\end{array}$ & $43(19-75)$ & $45(29-91)$ & 44 (19-91) & 0.575 \\
\hline
\end{tabular}


Table 1 (Continued)

\begin{tabular}{|c|c|c|c|c|}
\hline & $\begin{array}{l}\mathrm{p} 16+ \\
n=55\end{array}$ & $\begin{array}{l}\text { p16- } \\
n=9\end{array}$ & $\begin{array}{l}\text { All } \\
n=67\end{array}$ & $\begin{array}{l}\text { P-value } \\
\text { (p16+ vs. p16-) }\end{array}$ \\
\hline \multicolumn{5}{|l|}{ Pause in radiation treatment, $\%$} \\
\hline No & $44(80.0)$ & $7(77.8)$ & $54(80.6)$ & 1.000 \\
\hline Yes & $11(20.0)$ & $2(22.2)$ & $13(19.4)$ & \\
\hline Chemotherapy finished as planned, \% & $n=50$ & $n=8$ & $n=61$ & 0.124 \\
\hline Yes & $34(68.0)$ & $3(37.5)$ & $39(63.9)$ & \\
\hline No & $16(32.0)$ & $5(62.5)$ & $22(36.1)$ & \\
\hline \multicolumn{5}{|l|}{ Follow-up, months } \\
\hline Mean & 36 & 22 & 34 & 0.046 \\
\hline Median & 38 & 18 & 38 & \\
\hline Range & $3-61$ & $2-54$ & $2-61$ & \\
\hline Disease recurrence, $\%$ & $7(12.7)$ & $6(66.7)$ & $13(19.4)$ & 0.001 \\
\hline Residual disease at 3 months & $3(5.5)$ & $4(44.4)$ & $7(10.4)$ & \\
\hline Later recurrence & $4(7.2)$ & $2(22.2)$ & $6(9.0)$ & \\
\hline Time to recurrence, days, median, range & $216(71-885)$ & $85(64-412)$ & $98(64-885)$ & 0.138 \\
\hline Locoregional recurrence, \% & $5(9.1)$ & $6(66.7)$ & $11(16.4)$ & $<0.001$ \\
\hline Local & $1(1.8)$ & $5(55.6)$ & $6(9.0)$ & \\
\hline Neck & $4(7.3)$ & $3(33.3)$ & $6(9.0)$ & \\
\hline Distant metastasis, \% & $4(7.3)$ & $2(22.2)$ & $6(9.0)$ & 0.196 \\
\hline Overall survival, \% & $49(89.1)$ & $3(33.3)$ & $54(80.6)$ & $<0.001$ \\
\hline Disease-free survival, \% & $46(83.6)$ & $2(22.2)$ & $50(74.6)$ & $<0.001$ \\
\hline Disease-specific survival, \% & $51(92.7)$ & $4(44.4)$ & $58(86.6)$ & 0.002 \\
\hline
\end{tabular}

later recurrent disease in $6(9.0 \%)$. Median time to recurrence was 98 days. Follow-up time was calculated from the last day of treatment to the last follow-up visit or death, whichever occurred first. Salvage surgery included primary tumor area, or neck dissection, or both depending on the site of the recurrence.

\section{Pretreatment MRI and Analysis}

Our standard tumor imaging protocol consisted of a localizer sequence, axial turbo spin echo (TSE) T2, axial fat saturated T2, axial TSE T1, axial and coronal fat saturated T1 with gadolinium, and axial echo-planar DWI with b-values of 0,500 , and $1000 \mathrm{~s} / \mathrm{mm}^{2}$. ADC maps were generated from DWI sequences. The patients were imaged with six different MRI scanners: two were 1.5 T Siemens Avanto fit (Siemens Healthcare, Erlangen, Germany), two were $1.5 \mathrm{~T}$ Siemens Avanto (Siemens Healthcare), one was 1.5 T GE Signa HDxt (GE Healthcare, Chicago, IL, USA), and one was $3 \mathrm{~T}$ Siemens Verio (Siemens Healthcare). Dedicated head and neck coils were applied. Two experienced head and neck radiologists (H. S. and R. L.) analyzed the images, blinded to tumor p16 status and treatment outcome.

\section{Clinical and Radiological Variables}

All patient data were gathered from hospital records (Tables 1 and 2). Tumors primarily staged by the 7 th edition of the UICC system were retrospectively restaged according to the UICC 8th edition [1]. The p16 IHC served for determining the tumor HPV association. The criteria of the size of the metastatic node were minimum axial diameter of $10 \mathrm{~mm}$ and $11 \mathrm{~mm}$ for the digastric node [25]. Heterogeneous nodes were counted as metastatic. Cystic metastases were defined to have a thin $(<2 \mathrm{~mm})$ enhancing capsule and internal homogeneous fluid content [26], or as an intranodal cystic space with more than $70 \%$ of the border smoothly delineated [27]. Otherwise, a fluid-containing metastatic node was defined as necrotic. Lymph node location was documented according to the American Academy of Otolaryngology-Head and Neck Surgery (AAO-HNS) 2002 classification [28].

The volume of the primary tumor and the largest single metastasis or matted metastatic lymph node mass were measured by manually drawing the region of interest (ROI) in all MRI slides containing the tumor. Volume was measured primarily from the ADC maps, which usually well differentiate the tumor and surrounding edema. The T2 and $\mathrm{T} 1$ gadolinium-enhanced fat saturated images were used as a reference. If ADC maps were unavailable or tumor was not well delineated, T1 gadolinium-enhanced fat saturated 
Table 2 Radiological variables, stratified by p16, and interobserver correlations

\begin{tabular}{|c|c|c|c|c|c|}
\hline Variables & $\begin{array}{l}\mathrm{p} 16+ \\
n=55\end{array}$ & $\begin{array}{l}\text { p16- } \\
n=9\end{array}$ & $\begin{array}{l}\text { All } \\
n=67\end{array}$ & $\begin{array}{l}p \text {-value (difference between } \\
\text { p16+ and p16-) }\end{array}$ & $\begin{array}{l}\text { Interobserver corre- } \\
\text { lation }\end{array}$ \\
\hline \multicolumn{6}{|l|}{ Primary tumor } \\
\hline $\begin{array}{l}\text { Volume, } \mathrm{cm}^{3} \text {, mean } \\
\text { (range) }\end{array}$ & $8.1(0.7-35.3)$ & $18.6(3.6-39.8)$ & $10.7(0.7-92.5)$ & 0.034 & - \\
\hline $\begin{array}{l}\mathrm{ADC}_{\text {mean }}, 10^{-3} \mathrm{~mm}^{2} / \mathrm{s} \\
\text { (range) }\end{array}$ & $\begin{array}{l}0.747 \\
(0.496-1.233)\end{array}$ & $\begin{array}{l}0.966 \\
(0.838-1.045)\end{array}$ & $\begin{array}{l}0.784 \\
(0.496-1.233)\end{array}$ & $<0.001$ & 0.783 \\
\hline $\begin{array}{l}\mathrm{ADC}_{\min }, 10^{-3} \mathrm{~mm}^{2} / \mathrm{s} \\
\text { (range) }\end{array}$ & $\begin{array}{l}0.595 \\
(0.424-1.005)\end{array}$ & $\begin{array}{l}0.761 \\
(0.606-0.873)\end{array}$ & $\begin{array}{l}0.621 \\
(0.400-1.005)\end{array}$ & $<0.001$ & 0.797 \\
\hline Necrosis, $\%$ & $6(10.9)$ & $3(33.3)$ & $10(14.9)$ & 0.106 & 0.203 \\
\hline Ulceration, \% & $23(41.8)$ & $7(77.8)$ & $32(47.8)$ & 0.071 & 0.302 \\
\hline Inflammation, $\%$ & $36(65.5)$ & $7(77.8)$ & $45(67.1)$ & 0.706 & 0.451 \\
\hline Exophytic growth, \% & $34(61.8)$ & $2(22.2)$ & $37(55.2)$ & 0.035 & 0.528 \\
\hline $\begin{array}{l}\text { Well-delineated bor- } \\
\text { der, \% }\end{array}$ & $36(65.5)$ & $3(33.3)$ & $39(58.2)$ & 0.137 & 0.620 \\
\hline $\begin{array}{l}\text { Intense enhancement, } \\
\%\end{array}$ & $25(45.5)$ & $6(66.7)$ & $32(47.8)$ & 0.296 & 0.397 \\
\hline Muscle invasion, $\%$ & $20(36.4)$ & $6(66.7)$ & $28(41.8)$ & 0.142 & 0.624 \\
\hline \multicolumn{6}{|l|}{ Neck metastasis } \\
\hline \multicolumn{6}{|c|}{ Number of metastatic nodes } \\
\hline Mean & 2.6 & 2.9 & 2.6 & 0.732 & 0.517 \\
\hline Median & 2 & 3 & 2 & & \\
\hline Range & $0-10$ & $0-6$ & $0-10$ & & \\
\hline \multicolumn{6}{|l|}{ Location, \% } \\
\hline Ipsilateral & $42(76.4)$ & $3(33.3)$ & $46(68.7)$ & 0.179 & 0.950 \\
\hline Contralateral & $1(1.8)$ & - & $1(1.5)$ & & \\
\hline Bilateral & $8(14.5)$ & $3(33.3)$ & $12(17.9)$ & & \\
\hline \multicolumn{6}{|l|}{ Diameter, cm } \\
\hline Mean & 3.6 & 2.8 & 3.6 & 0.092 & - \\
\hline Range & $1.2-11.1$ & $2.2-4.9$ & $1.2-11.1$ & & \\
\hline Volume, $\mathrm{cm}^{3}$ & $15.2(0.6-56.0)$ & $14.4(2.8-37.8)$ & $14.9(0.6-56.0)$ & 0.747 & - \\
\hline $\begin{array}{l}A D C_{\text {mean }}, 10^{-3} \mathrm{~mm}^{2} / \mathrm{s} \\
\text { (range) }\end{array}$ & $\begin{array}{l}0.783 \\
(0.537-1.483)\end{array}$ & $\begin{array}{l}0.955 \\
(0.818-1.141)\end{array}$ & $\begin{array}{l}0.802 \\
(0.537-1.483)\end{array}$ & 0.013 & 0.913 \\
\hline $\begin{array}{l}\text { ADC } \min , 10^{-3} \mathrm{~mm}^{2} / \mathrm{s} \\
\text { (range) }\end{array}$ & $\begin{array}{l}0.622 \\
(0.366-0.974)\end{array}$ & $\begin{array}{l}0.797 \\
(0.628-0.904)\end{array}$ & $\begin{array}{l}0.638 \\
(0.366-0.974)\end{array}$ & 0.007 & 0.820 \\
\hline $\begin{array}{l}\text { Extranodal extension, } \\
\%\end{array}$ & 35 (63.6) & $5(55.6)$ & $41(61.2)$ & 0.718 & 0.708 \\
\hline Matted nodes, \% & $18(32.7)$ & $3(33.3)$ & $21(31.3)$ & 1.000 & 0.895 \\
\hline Solid nodes, \% & $9(16.4)$ & $9(100)$ & $9(13.4)$ & 0.337 & 0.872 \\
\hline Necrotic nodes, $\%$ & $21(38.2)$ & $3(33.3)$ & $24(35.8)$ & 1.000 & 0.499 \\
\hline Cystic nodes, \% & $19(34.5)$ & $3(33.3)$ & $23(34.3)$ & 1.000 & 0.516 \\
\hline
\end{tabular}

$A D C$ apparent diffusion coefficient

images were used instead. Prior to volume measurement, MR images were exported from our picture archiving and communication system (Agfa Impax 6.7, Agfa Healthcare, Mortsel, Belgium) and anonymized. Volume measurement was performed with third party 3D software (3D Slicer version 4.10.1, www.slicer.org).

\section{DWI Analysis}

The $\mathrm{ADC}_{\text {mean }}$ of the primary tumor and metastatic lymph node was measured by manually drawing an ROI on the single slice most central to the tumor (Fig. 2). The T2 and $\mathrm{T} 1$ fat saturated gadolinium-enhanced images served as a reference to exclude necrotic areas. $\mathrm{ADC}_{\min }$ was measured with the smallest available $0.24 \mathrm{~cm}^{2}$ ROI from the most hypointense part of the tumor. 
Fig. 2 Measuring apparent diffusion coefficient (ADC) region of interest (ROI). a Axial diffusion weighted imaging, $\mathbf{b}$ corresponding ADC map and $\mathbf{c}$ axial T1 fat saturated gadolinium-enhanced images show a tonsillar tumor infiltrating to the tongue on the right. The ROI was drawn on the ADC map along the tumor borders, excluding the surrounding inflammation and necrotic areas, on the most central slice of the tumor. The ADC was $1.097 \times 10^{-3} \mathrm{~mm}^{2} / \mathrm{s}$
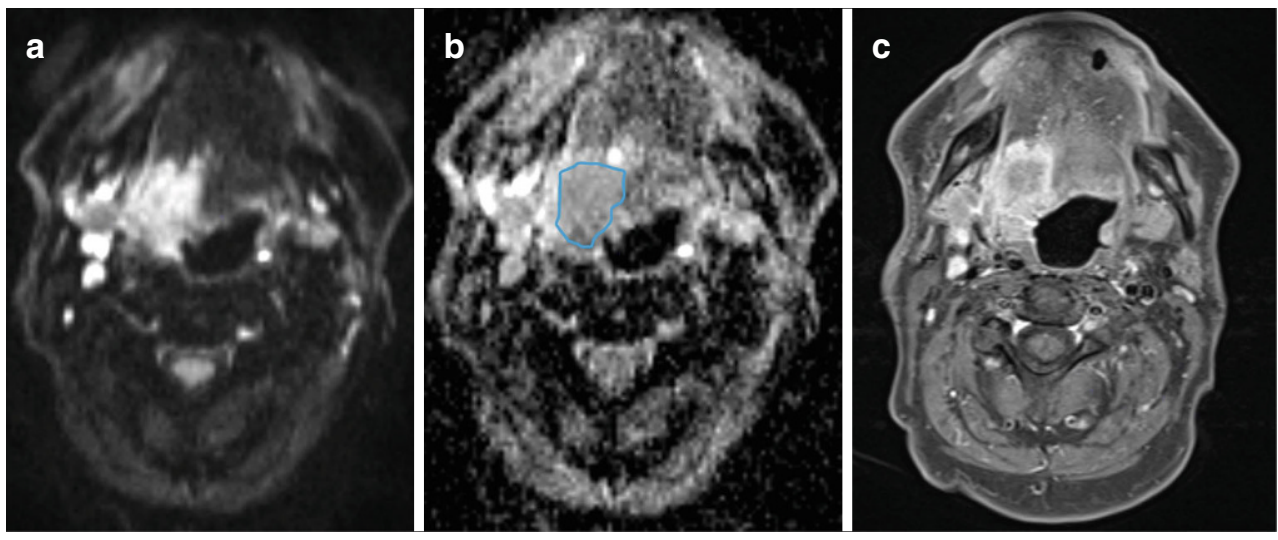

The ADC values differ between MRI systems and ADC value of the cervical spinal cord may be used to compare between these differences [29]. In an attempt to estimate the ADC values across different scanners, we measured ADC at the level of cervical spinal cord in 3 central slices to calculate a mean value $\left(\mathrm{ADC}_{\text {myelum }}\right)$ for each examination.

\section{Statistical Analysis}

The main clinical outcome measures were disease-free survival (DFS) and LRR rate, as we found them to be most representative of the treatment effect in our study setting. Time to event or censoring was counted from the end date of (C)RT. We first conducted univariable Cox proportional hazards model to find potential prognostic factors, then adjusted the results with the tumor p16-status.

Differences in variable values between p16-positive and p16-negative tumors were compared with $\chi^{2}$-testor Fisher's exact test with categorical variables and Mann-Whitney U-nonparametric test with ordinal or continuous variables, which in our study were all non-normally distributed. Interobserver agreement for categorical radiological variables was calculated with Cohen's kappa and in continuous variables with intraclass correlation coefficient (ICC). Values under 0.4 indicated poor agreement, values between 0.4 and 0.75 indicated moderate agreement, and values 0.75 and over indicated excellent agreement [30]. Variables with poor interobserver agreement were not studied.

The differences between MRI systems were evaluated by comparing the mean value of $\mathrm{ADC}_{\text {myelum }}$ for each MRI system examinations with Kruskal-Wallis nonparametric test. A $p$-value of $<0.05$ was considered significant.

The data analysis tool was SPSS Statistics 25 software (SPSS Inc., Chicago, IL, USA). Survival curves were drawn using GraphPad Prism (version 9.0 for Windows, Graphpad software, La Jolla, CA, USA, www.graphpad.com).

\section{Results}

\section{Patients}

Table 1 presents patient demographics, treatment outcome, and survival data, stratified by tumor p16 status. In patients with p16-negative disease, both overall survival (OS) and DFS were noticeably inferior. Of the 13 patients with LRR, further treatment included surgery with curative intent in 5 patients, palliative radiotherapy in 1 patient, palliative chemotherapy in 2 patients, palliative CRT in 2 patients, and palliative symptomatic treatment in 2 patients. One patient died of hemorrhage at the time of diagnosis of the recurrent tumor.

Thirteen patients experienced a treatment break in RT ranging from 2-18 days (median 6 days). In total, 39 patients received chemotherapy as planned. Three patients received a chemotherapy agent other than cisplatin.

\section{Prognostic Value of Clinical and Radiological Variables for DFS (Table 3)}

In univariable analysis, patients with p16-negative tumor had a 7.7-fold risk for disease recurrence or death compared with patients with p16-positive tumor. Smoking at diagnosis and number of pack years were also significantly associated with worse DFS. Interruptions in RT and incomplete chemotherapy were significantly associated with worse DFS. After adjusting for these variables with p16, only interruption of RT remained significant in DFS analysis.

In univariable analysis, metastasis volume, muscle invasion, and depth of muscle invasion indicated significantly worse DFS. Primary tumor higher $\mathrm{ADC}_{\text {mean }}$ and $\mathrm{ADC}_{\text {min }}$ were associated with worse DFS. After adjusting these variables with p16, only metastasis volume remained significant in DFS analysis. Larger metastasis volume but not primary tumor volume, was associated with the occurrence of distant metastasis, regardless of p16 status. The HR was 1.059 
Table 3 Crude and p16-adjusted hazard ratios (HR) for disease-free survival in Cox proportional hazards regression model

\begin{tabular}{|c|c|c|c|c|}
\hline Variable & $\begin{array}{l}\text { All patients } n=67 \\
\text { Crude HR }(95 \% \mathrm{CI})\end{array}$ & $p$ & $\begin{array}{l}\text { p16-adjusted HR (95\% } \\
\text { CI) }\end{array}$ & $p$ \\
\hline$\overline{\text { Age }}$ & $1.040(0.986-1.096)$ & 0.147 & $1.044(0.984-1.107)$ & 0.155 \\
\hline Smoking (at diagnosis vs. no/earlier) & $3.178(1.152-8.765)$ & 0.026 & $1.122(0.236-5.333)$ & 0.885 \\
\hline Pack years & $1.039(1.005-1.074)$ & 0.025 & $1.025(0.981-1.071)$ & 0.279 \\
\hline Alcohol use (current vs. previous/never) & $2.771(0.794-9.664)$ & 0.110 & $1.249(0.294-5.299)$ & 0.763 \\
\hline T-stage (7th ed. T3-4 vs. T1-2) & $2.140(0.825-5.553)$ & 0.118 & $1.297(0.448-3.751)$ & 0.632 \\
\hline T-stage (8th ed. T3-4 vs. T1-2) & $1.731(0.668-4.490)$ & 0.259 & $0.980(0.334-2.875)$ & 0.971 \\
\hline $\mathrm{N}$-stage (N+ vs. N0) & $0.305(0.112-0.828)$ & 0.020 & $0.585(0.180-1.898)$ & 0.372 \\
\hline $\mathrm{N}$-stage (N2+ vs. N0-1) & $2.026(0.712-5.760)$ & 0.186 & $0.921(0.259-3.284)$ & 0.900 \\
\hline Stage (III-IV vs. I-II) & $2.050(0.742-5.663)$ & 0.166 & $0.950(0.295-3.063)$ & 0.932 \\
\hline p16 (negative vs. positive) & $7.674(2.832-20.800)$ & $<0.001$ & - & - \\
\hline Grade (grade 3 vs. grades $1-2$ ) & $0.268(0.101-0.716)$ & 0.009 & $0.799(0.203-3.149)$ & 0.749 \\
\hline Break in radiation treatment (yes vs. no) & $3.583(1.358-9.457)$ & 0.010 & $3.972(\mathrm{q})$ & 0.007 \\
\hline Incomplete chemotherapy (yes vs. no) & $3.086(1.096-8.693)$ & $\mathbf{0 . 0 3 3}$ & $1.936(0.638-5.877)$ & 0.243 \\
\hline \multicolumn{5}{|l|}{ Radiological variables } \\
\hline Primary tumor volume & $1.004(0.976-1.033)$ & 0.783 & $1.009(0.966-1.054)$ & 0.690 \\
\hline Primary tumor volume $\left(>7 \mathrm{~cm}^{3}\right.$ vs. $\left.\leq 7 \mathrm{~cm}^{3}\right)$ & $2.209(0.816-5.975)$ & 0.119 & $2.131(0.762-5.959)$ & 0.149 \\
\hline Primary tumor transverse diameter & $1.399(0.952-2.054)$ & 0.087 & $1,618(0.936-2.796)$ & 0.085 \\
\hline Primary tumor $\mathrm{ADC}_{\text {mean }}$ & $21.780(1.151-412.019)$ & 0.040 & $0.751(0.007-83.525)$ & 0.905 \\
\hline Primary tumor $\mathrm{ADC}_{\min }$ & $40.775(1.647-1009.699)$ & 0.024 & $0.933(0.008-107.248)$ & 0.977 \\
\hline Muscle invasion (yes vs. no) & $2.785(1.043-7.439)$ & 0.041 & $2.342(0.818-6.701)$ & 0.113 \\
\hline Invasion depth & $1.504(1.006-2.247)$ & 0.047 & $1.329(0.874-2.022)$ & 0.184 \\
\hline Metastasis volume & $1.036(1.003-1.069)$ & $\mathbf{0 . 0 3 4}$ & $1.041(1.007-1.077)$ & $\mathbf{0 . 0 1 9}$ \\
\hline Metastasis volume $\left(>13 \mathrm{~cm}^{3}\right.$ vs. $\left.\leq 13 \mathrm{~cm}^{3}\right)$ & $2.540(0.825-7.820)$ & 0.104 & $2.384(0.758-7.492)$ & 0.137 \\
\hline Metastasis ENE & $0.659(0.254-1.710)$ & 0.391 & $0.827(0.303-2.259)$ & 0.712 \\
\hline Metastasis $\mathrm{ADC}_{\text {mean }}$ & $2.128(0.096-47.281)$ & 0.633 & $0.990(0.020-50.115)$ & 0.996 \\
\hline Metastasis $\mathrm{ADC}_{\min }$ & $6.658(0.079-563.032)$ & 0.402 & $0.974(0.005-202.478)$ & 0.992 \\
\hline
\end{tabular}

$A D C$ apparent diffusion coefficient, $E N E$ extranodal extension, $C I$ confidence interval

(95\% CI 1.011-1.110, $p=0.015$ ). Survival curves stratified by $\mathrm{ADC}$ are presented in Fig. 3a, b.

\section{Prognostic Value of Clinical and Radiological Variables in LRR (Table 4)}

In univariable analysis, LRR rate was associated with p16 and higher T-stage, stage, and grade. After adjusting these variables with $\mathrm{p} 16$, none of these clinical variables remained significant in LRR rate analysis.

Univariable analysis showed prognostic value for primary tumor volume, transverse diameter, anteroposterior diameter, muscle invasion, and invasion depth. After adjustment with $\mathrm{p} 16$, primary tumor volume had significant association with the LRR rate. This was a two-class variable, where tumors were divided by the median, to $\leq 7 \mathrm{~cm}^{3}$ and $>7 \mathrm{~cm}^{3}$. Primary tumor transverse diameter was also significantly associated with worse prognosis, whilst ADC values showed no significance. In p16-positive tumors, ADC values were significantly higher in grade 1-2 tumors (mean $0.883)$ compared to grade 3 tumors $(0.736 ; p=0.003)$. In these patients, tumor grade had no effect on treatment outcome.

\section{Differences in ADC Measurements Between Different MRI Systems}

The $\mathrm{ADC}_{\text {myelum }}$ values in different MRI systems were significantly different between separate $1.5 \mathrm{~T}$ systems, and also between $1.5 \mathrm{~T}$ and $3 \mathrm{~T}$ systems $(p=0.007)$. After Bonferroni correction for multiple tests, the differences were no longer statistically significant.

\section{Interobserver Correlations}

For the primary tumor the intraclass correlation coefficient (ICC) for $\mathrm{ADC}_{\text {mean }}$ was 0.783 and for $\mathrm{ADC}_{\text {min }} 0.797$ and for metastasis 0.913 and 0.820 , respectively. We observed a relatively inferior Cohen's kappa $(\kappa)$ interobserver agreement in evaluating necrotic and cystic nodes $(\kappa=0.499$ and $\kappa=0.516$, respectively, Table 2). Fig. 4 demonstrates examples of cystic and necrotic metastases. 
Table 4 Crude and p16-adjusted hazard ratios (HR) for locoregional recurrence rate in Cox proportional hazards regression model

\begin{tabular}{|c|c|c|c|c|}
\hline Variable & $\begin{array}{l}\text { All patients } n=67 \\
\text { Crude HR }(95 \% \text { CI) }\end{array}$ & $p$ & $\begin{array}{l}\text { p16-adjusted HR (95\% } \\
\text { CI) }\end{array}$ & $p$ \\
\hline$\overline{\text { Age }}$ & $1.055(0.986-1.128)$ & 0.119 & $1.047(0.974-1.125)$ & 0.212 \\
\hline Smoking (at diagnosis vs. no/earlier) & $2.270(0.692-7.445)$ & 0.176 & $0.194(0.11-3.396)$ & 0.261 \\
\hline Pack years & $1.044(0.998-1.092)$ & 0.060 & $1.027(0.967-1.089)$ & 0.387 \\
\hline Alcohol use (current vs. previous/never) & $2.912(0.629-13.488)$ & 0.172 & $1.524(0.291-7.973)$ & 0.618 \\
\hline T-stage (7th ed. T3-4 vs. T1-2) & $4.983(1.320-18.807)$ & 0.018 & $2.975(0.715-12.379)$ & 0.134 \\
\hline T-stage (8th ed. T3-4 vs. T1-2) & $3.388(0.991-11.584)$ & 0.052 & $1.861(0.484-7.150)$ & 0.366 \\
\hline $\mathrm{N}$-stage (N+ vs. N0) & $0.447(0.118-1.688)$ & 0.235 & $10.462(2.962-36.959)$ & 0.735 \\
\hline $\mathrm{N}$-stage (N2+ vs. N0-1) & $2.678(0.784-9.155)$ & 0.116 & $0.771(0.182-3.259)$ & 0.724 \\
\hline Stage (III-IV vs. I-II) & $3.912(1.192-12.834)$ & 0.024 & $1.550(0.382-6.285)$ & 0.540 \\
\hline p16 (negative vs. positive) & $11.170(3.378-36.931)$ & $<0.001$ & - & - \\
\hline Grade (grade 3 vs. grades 1-2) & $0.231(0.071-0.759)$ & 0.016 & $0.648(0.132-3.186)$ & 0.593 \\
\hline Break in radiation treatment (yes vs. no) & $2.639(0.772-9.024)$ & 0.122 & $2.918(0.487-17.474)$ & 0.241 \\
\hline Incomplete chemotherapy (yes vs. no) & $1.905(0.551-6.583)$ & 0.308 & $1.141(0.308-4.225)$ & 0.843 \\
\hline \multicolumn{5}{|l|}{ Radiological variables } \\
\hline Primary tumor volume & $1.016(0.989-1.045)$ & 0.242 & $1.023(0.977-1.072)$ & 0.328 \\
\hline Primary tumor volume $\left(>7 \mathrm{~cm}^{3}\right.$ vs. $\left.\leq 7 \mathrm{~cm}^{3}\right)$ & $5.282(1.140-24.459)$ & $\mathbf{0 . 0 3 3}$ & $4.861(1.042-22.667)$ & 0.044 \\
\hline Primary tumor transverse diameter & $1.776(1.141-2.766)$ & 0.011 & $2.273(1.210-4.269)$ & 0.011 \\
\hline Primary tumor AP diameter & $1.837(1.099-3.069)$ & $\mathbf{0 . 0 2 0}$ & $1.274(0.775-2.096)$ & 0.339 \\
\hline Primary tumor $\mathrm{ADC}_{\text {mean }}$ & $28.548(0.812-1003.839)$ & 0.065 & $0.760(0.002-293.529)$ & 0.928 \\
\hline Primary tumor $\mathrm{ADC}_{\min }$ & $25.267(0.484-1320.121)$ & 0.110 & $0.343(0.001-112.207)$ & 0.717 \\
\hline Muscle invasion (yes vs. no) & $7.472(1.612-34.624)$ & 0.010 & $7.722(0.862-69.145)$ & 0.068 \\
\hline Invasion depth & $2.025(1.311-3.126)$ & $<0.001$ & $1.539(0.965-2.453)$ & 0.070 \\
\hline Metastasis volume & $1.023(0.982-1.065)$ & 0.275 & $1.027(0.984-1.072)$ & 0.228 \\
\hline Metastasis volume $\left(>13 \mathrm{~cm}^{3}\right.$ vs. $\left.\leq 13 \mathrm{~cm}^{3}\right)$ & $1.398(0.409-4.775)$ & 0.593 & $1.390(0.406-4.756)$ & 0.600 \\
\hline Metastasis ENE & $1.056(0.309-3.608)$ & 0.931 & $1.113(0.322-3.843)$ & 0.866 \\
\hline Metastasis $\mathrm{ADC}_{\text {mean }}$ & $6.631(0.292-150.793)$ & 0.235 & $3.924(0.061-253.100)$ & 0.520 \\
\hline Metastasis $\mathrm{ADC}_{\min }$ & $54.659(0.373-8003.590)$ & 0.116 & $9.283(0.018-4853.235)$ & 0.485 \\
\hline
\end{tabular}

$A P$ anteroposterior, $A D C$ apparent diffusion coefficient, $E N E$ extranodal extension, $C I$ confidence interval

\section{Discussion}

To our knowledge this is the first study analyzing prognostic imaging factors in OPSCC and including a considerable number of p16 positive OPSCC patients. Our main finding was that our results do not support the hypothesis that ADC would be an independent prognostic factor. Higher $\mathrm{ADC}_{\text {mean }}$ and $\mathrm{ADC}_{\min }$ were associated with lower DFS in univariable analysis but not after adjustment with the p16 status. This finding may be explained by the fact that ADC correlates with tumor p16 status [21, 22], which in itself is a strong predictor of disease recurrence and survival [31, 32].

Most studies evaluating the role of pretreatment ADC in predicting the results of (C)RT in different head and neck sites linked high ADC to worse prognosis [7, 9-16], while some showed no connection [17, 19, 33]. Interestingly, one study associated low ADC to worse 2-year DFS, but over half of the patients were surgically treated [18]. Since previous studies have not differentiated results by site, it is hard to tell if ADC has real prognostic effect in cancers in other head and neck anatomic sites or if results are confounded because of the HPV-associated effects in ADC and survival among OPSCC.

In our study, among the $\mathrm{p} 16$ positive subgroup, $\mathrm{ADC}$ values were significantly higher in grade 2 tumors compared to grade 3 tumors. Similar observations have been previously reported in meningiomas [34], gliomas [35], and a nonsignificant correlation was found in oral and oropharyngeal cancers [36]. A study comparing histology to ADC values in laryngeal and hypopharyngeal cancers discovered that ADC correlated inversely with cell density, nuclear area, and nuclear-cytoplasmic ratio. ADC also correlated positively with the percentage area of stroma [37]. HPV-associated tumors are typically nonkeratinizing or only partially keratinizing, may have areas of central necrosis and cystic changes, and host tumor infiltrating lymphocytes. They often lack a strong stromal desmoplastic reaction and have a lower stromal volume [38]. Many of these characteristics can contribute to both lower ADC and better response to RT. HPV-associated cancer also has intrinsic genetic mech- 
All patients according to ADC

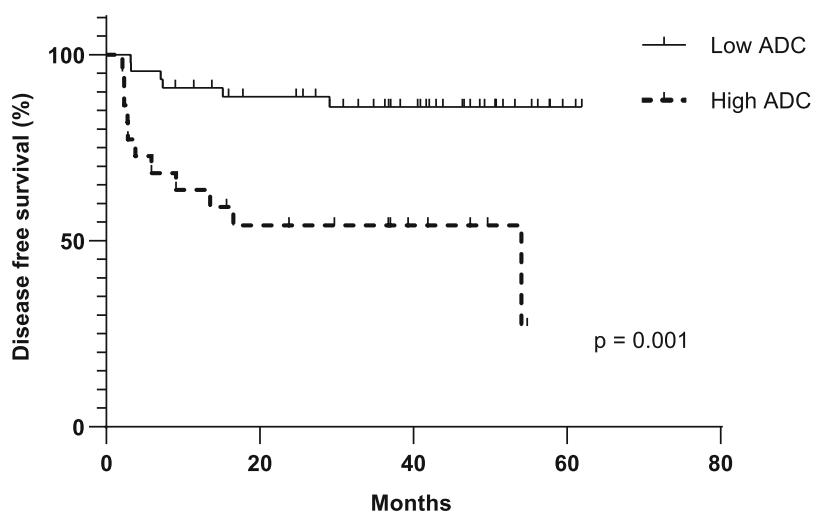

b

p16-positive tumors according to ADC and p16-negative tumors

Fig. 3 a Survival curves for all patients (p16-positive and p16-negative tumors). Disease-free survival (DFS) in two groups of primary tumor apparent diffusion coefficient $\left(\mathrm{ADC}_{\text {mean }}\right.$ ) at or higher than $0.836 \times 10^{-3} \mathrm{~mm}^{2} / \mathrm{s}$, and lower than $0.836 \times 10^{-3} \mathrm{~mm} / \mathrm{s}, p=0.001$. b Survival curves for patients with p16-positive and p16-negative tumors. In p16-positive patients, disease-free survival (DFS) was represented in two groups of primary tumor apparent diffusion coefficient $\left(\mathrm{ADC}_{\text {mean }}\right)$ : at or higher than $0.772 \times 10^{-3} \mathrm{~mm}^{2} / \mathrm{s}$, and lower than $0.772 \times 10^{-3} \mathrm{~mm}^{2} / \mathrm{s}, p=0.604$. Difference between mean $\mathrm{ADC}_{\text {mean }}$ between p16-positive and p16-negative tumors was statistically significant $(p<0.001)$
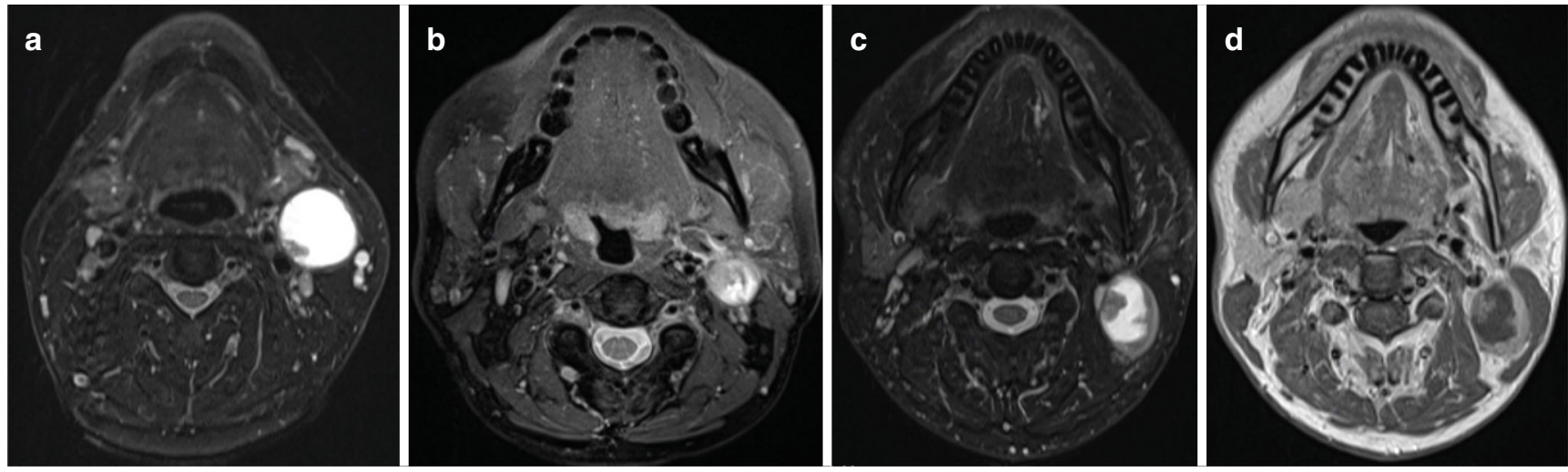

Fig. 4 Examples of cystic and necrotic metastases. a T2 fat saturated image of a metastasis that was clearly cystic, with a thin capsule and homogeneous fluid, with only a minor wall irregularity. b Example of a necrotic node in a T2 fat saturated image, with a mainly irregular margin between fluid and solid parts. c The third example is of a metastasis that the radiologists graded differently. The margin appears smooth in T2 fat saturated image but (d) reveals more irregularity in T1 gadolinium-enhanced image, leading the other radiologist to grade the metastasis as necrotic. All three tumors were p16-positive

anisms, which might explain the radiation sensitivity [39]. Microscopic necrosis could also explain higher ADC, with hypoxia-initiating cellular survival mechanisms making the tumor less sensitive to RT, but so far hypoxia-related markers have not been found to be related to higher ADC [37, 40].

As presented in Table 2, even with a small number of patients, it appears that ADC values in p16-positive primary tumors and metastases were significantly lower compared to p16-negative tumors, which is in line with a previous systematic review and meta-analysis [22]. The p16-positive tumors were smaller and more often exophytic than not, similar to previous studies [41, 42]. Our cohort lacked any significant differences in the rates of cystic, necrotic, and solid metastases in relation to p16 status. This is in contrast to previous studies reporting a larger number of cystic metastases in p16-positive patients [26, 41, 42], while the limited number of p16-negative tumors might influence this assessment. Although cystic and necrotic nodes are clearly defined, in our study radiologists found the evaluation often challenging, which was reflected in the suboptimal interobserver correlation. On the contrary, other lymph node characteristics, such as ENE and matted nodes, showed better interobserver correlations.

We drew the ROI on the ADC maps with a free-hand method on the most central slice. We feel that this best resembles our available tools in everyday clinical practice and is easy to produce. The interobserver correlations for the ADC values were excellent. The ADC results in our study, however, may consequently differ from the studies that used automatic or semi-automatic segmentation. The different MRI systems used in this study bring forth vari- 
ability in ADC values. These differences were observable in our measurements but were not statistically significant after Bonferroni correction for multiple tests.

We found a correlation between larger metastasis volume and worse DFS, regardless of p16 association. This is similar to a Finnish study comprising 91 OPSCC patients that found nodal volume to correlate with DFS and locoregional control both in p16-negative and p16-positive disease [8]. Davis et al. [43] also found that in HPV-positive OPSCC, smaller nodal volume led to better DFS. In our study, the LRR rate was higher in patients with a primary tumor volume over $7 \mathrm{~cm}^{3}$. The aforementioned reports failed to show similar results $[8,43]$. In tonsillar tumors with unknown HPV association, the connection disappeared after taking the T-stage into consideration [44]. Carpén et al. [8], however, observed a connection between larger primary tumor volume and worse OS in p16-negative disease. Interestingly, metastasis volume, but not primary tumor volume, correlated with survival in our study. This might be connected to our finding that larger neck metastasis volume but not larger primary tumor volume, correlated significantly with occurrence of later distant metastasis. A recent study showed that disease recurred only in OPSCC patients with persisting high risk HPV positivity after treatment [45]. In our hospital, we do not routinely determine the HPV status after treatment, although this might be worth considering in the future.

An unplanned break in radiation treatment led to worse DFS. The break duration was between 2-18 days, with most patients having mid-treatment breaks of under 10 days. In head and neck cancers, treatment breaks are known to decrease survival and local control [46, 47], tumor cell repopulation being faster during the break [48]. Incomplete radiotherapy seems to affect particularly the more radiosensitive HPV-associated oropharyngeal cancers [49].

In Finland surgery is usually the treatment of choice for patients with p16-negative tumors; however, (C)RT may be the option e.g., if surgery is expected to cause significant morbidity. We decided to include all patients treated with (C)RT with curative intent as our aim was neither a comparison of treatment modalities nor comparison of prognosis between p16-negative and p16-positive groups, and the final analysis accounted for the p16 status. This led to a small number of patients with p16-negative OPSCC in our cohort, and the recurrence rate and survival probably not being representative of the whole population with p16-negative tumors. Because of the small number of p16-negative OPSCC patients, and the generally good prognosis among the p16positive OPSCC patients, event count remains fairly small and our survival analysis results must be interpreted with caution. To be able to obtain statistical power, we adjusted our survival analyses with p16 status only, as it is the most important factor affecting prognosis in OPSCC [31, 32].
One of the limitations in our study is use of ADC and p16 in the same Cox proportional hazards model as they have a strong statistical correlation; however, the observation that any prognostic impact of ADC remained absent in the p16positive group supports our main finding of ADC being merely an indication of HPV status.

\section{Conclusion}

Our study showed that in patients with OPSCC and with known p16 status, pretreatment tumor ADC values provide no additional benefit in evaluating prognosis after definitive (C)RT with curative intent. Our results indicate that ADC values should not be used to select patients for de-escalation trials or lighter treatment.

Funding This study was supported by the Helsinki University Hospital Research Fund.

Author Contribution Conceptualization: H. Sistonen, K. Aro, T. Atula, A. Markkola; data curation: H. Sistonen, R. Lindén, L. Tapiovaara, V. Loimu, A. Markkola; formal analysis: H. Sistonen, L. Jouhi; methodology: H. Sistonen, K. Aro, T. Atula, L. Jouhi, A. Markkola; supervision: K. Aro, T. Atula, A. Markkola; data interpretation: All authors; writing: original draft: H. Sistonen, K. Aro, T. Atula, A. Markkola; writing: review and editing: All authors

Funding Open access funding provided by University of Helsinki including Helsinki University Central Hospital.

\section{Declarations}

Conflict of interest H.J. Sistonen, K. Aro, T. Atula, L. Jouhi, R. Lindén, L. Tapiovaara, V. Loimu and A. Markkola declare that they have no conflicting interests.

Ethical standards The hospital ethics committee approved the study protocol and permission for an institutional study was granted. It has therefore been performed in accordance with the ethical standards laid down in the 1964 Declaration of Helsinki and its later amendments. The need for informed consent was waived because of the retrospective nature of the study.

Open Access This article is licensed under a Creative Commons Attribution 4.0 International License, which permits use, sharing, adaptation, distribution and reproduction in any medium or format, as long as you give appropriate credit to the original author(s) and the source, provide a link to the Creative Commons licence, and indicate if changes were made. The images or other third party material in this article are included in the article's Creative Commons licence, unless indicated otherwise in a credit line to the material. If material is not included in the article's Creative Commons licence and your intended use is not permitted by statutory regulation or exceeds the permitted use, you will need to obtain permission directly from the copyright holder. To view a copy of this licence, visit http://creativecommons.org/licenses/by/4. $0 /$. 


\section{References}

1. Brierley JD, Gospodarowicz MK, Wittekind C, eds. TNM classification of malignant tumours. John Wiley \& Sons, 2017.

2. El-Naggar AK, Chan JKC, Grandis JR, Takata T, Slootweg PJ, editors. WHO classification of head and neck tumours. 4th ed. Lyon: IARC Publications; 2017.

3. Masterson L, Moualed D, Liu ZW, Howard JE, Dwivedi RC, Tysome JR, Benson R, Sterling JC, Sudhoff H, Jani P, Goon PK. De-escalation treatment protocols for human papillomavirus-associated oropharyngeal squamous cell carcinoma: a systematic review and meta-analysis of current clinical trials. Eur J Cancer. 2014;50:2636-48.

4. Mirghani H, Blanchard P. Treatment de-escalation for HPV-driven oropharyngeal cancer: where do we stand? Clin Transl Radiat Oncol. 2018;8:4-11.

5. Rath TJ, Narayanan S, Hughes MA, Ferris RL, Chiosea SI, Branstetter BF 4th. Solid Lymph Nodes as an Imaging Biomarker for Risk Stratification in Human Papillomavirus-Related Oropharyngeal Squamous Cell Carcinoma. AJNR Am J Neuroradiol. 2017;38:1405-10.

6. Vainshtein JM, Spector ME, Ibrahim M, Bradford CR, Wolf GT, Stenmark MH, Worden FP, McHugh JB, Prince ME, Carey T, Chepeha DB, Eisbruch A. Matted nodes: High distant-metastasis risk and a potential indication for intensification of systemic therapy in human papillomavirus-related oropharyngeal cancer. Head Neck. 2016;38(Suppl 1):E805-14.

7. Ohnishi K, Shioyama Y, Hatakenaka M, Nakamura K, Abe K, Yoshiura T, Ohga S, Nonoshita T, Yoshitake T, Nakashima T, Honda $H$. Prediction of local failures with a combination of pretreatment tumor volume and apparent diffusion coefficient in patients treated with definitive radiotherapy for hypopharyngeal or oropharyngeal squamous cell carcinoma. J Radiat Res. 2011;52:522-30.

8. Carpén T, Saarilahti K, Haglund C, Markkola A, Tarkkanen J, Hagström J, Mattila P, Mäkitie A. Tumor volume as a prognostic marker in p16-positive and p16-negative oropharyngeal cancer patients treated with definitive intensity-modulated radiotherapy. Strahlenther Onkol. 2018;194:759-70.

9. Kim S, Loevner L, Quon H, Sherman E, Weinstein G, Kilger A, Poptani H. Diffusion-weighted magnetic resonance imaging for predicting and detecting early response to chemoradiation therapy of squamous cell carcinomas of the head and neck. Clin Cancer Res. 2009;15:986-94.

10. Hatakenaka M, Shioyama Y, Nakamura K, Yabuuchi H, Matsuo Y, Sunami S, Kamitani T, Yoshiura T, Nakashima T, Nishikawa K, Honda H. Apparent diffusion coefficient calculated with relatively high b-values correlates with local failure of head and neck squamous cell carcinoma treated with radiotherapy. AJNR Am J Neuroradiol. 2011;32:1904-10.

11. Chawla S, Kim S, Dougherty L, Wang S, Loevner LA, Quon H, Poptani H. Pretreatment diffusion-weighted and dynamic contrastenhanced MRI for prediction of local treatment response in squamous cell carcinomas of the head and neck. AJR Am J Roentgenol. 2013;200:35-43.

12. Ng SH, Lin CY, Chan SC, Lin YC, Yen TC, Liao CT, Chang JT, Ko SF, Wang HM, Chang CJ, Wang JJ. Clinical utility of multimodality imaging with dynamic contrast-enhanced MRI, diffusion-weighted MRI, and 18F-FDG PET/CT for the prediction of neck control in oropharyngeal or hypopharyngeal squamous cell carcinoma treated with chemoradiation. PLoS One. 2014;9:e115933.

13. Lambrecht M, Van Calster B, Vandecaveye V, De Keyzer F, Roebben I, Hermans R, Nuyts S. Integrating pretreatment diffusion weighted MRI into a multivariable prognostic model for head and neck squamous cell carcinoma. Radiother Oncol. 2014;110:429-34.

14. Preda L, Conte G, Bonello L, Giannitto C, Travaini LL, Raimondi S, Summers PE, Mohssen A, Alterio D, Cossu Rocca M, Grana C, Ruju F, Bellomi M. Combining standardized uptake value of FDGPET and apparent diffusion coefficient of DW-MRI improves risk stratification in head and neck squamous cell carcinoma. Eur Radiol. 2016;26:4432-41.

15. Noij DP, Pouwels PJW, Ljumanovic R, Knol DL, Doornaert P, de Bree R, Castelijns JA, de Graaf P. Predictive value of diffusionweighted imaging without and with including contrast-enhanced magnetic resonance imaging in image analysis of head and neck squamous cell carcinoma. Eur J Radiol. 2015;84:108-16.

16. Lombardi M, Cascone T, Guenzi E, Stecco A, Buemi F, Krengli M, Carriero A. Predictive value of pre-treatment apparent diffusion coefficient (ADC) in radio-chemiotherapy treated head and neck squamous cell carcinoma. Radiol Med. 2017;122:345-52.

17. Peltenburg B, Driessen JP, Vasmel JE, Pameijer FA, Janssen LM, Terhaard CHJ, de Bree R, Philippens MEP. Pretreatment ADC is not a prognostic factor for local recurrences in head and neck squamous cell carcinoma when clinical T-stage is known. Eur Radiol. 2020;30:1228-31.

18. Nakajo M, Nakajo M, Kajiya Y, Tani A, Kamiyama T, Yonekura R, Fukukura Y, Matsuzaki T, Nishimoto K, Nomoto M, Koriyama C. FDG PET/CT and diffusion-weighted imaging of head and neck squamous cell carcinoma: comparison of prognostic significance between primary tumor standardized uptake value and apparent diffusion coefficient. Clin Nucl Med. 2012;37:475-80.

19. King AD, Mo FK, Yu KH, Yeung DK, Zhou H, Bhatia KS, Tse GM, Vlantis AC, Wong JK, Ahuja AT. Squamous cell carcinoma of the head and neck: diffusion-weighted MR imaging for prediction and monitoring of treatment response. Eur Radiol. 2010;20:2213-20.

20. Driessen JP, van Bemmel AJ, van Kempen PM, Janssen LM, Terhaard $\mathrm{CH}$, Pameijer FA, Willems SM, Stegeman I, Grolman W, Philippens ME. Correlation of human papillomavirus status with apparent diffusion coefficient of diffusion-weighted MRI in head and neck squamous cell carcinomas. Head Neck. 2016;38 Suppl 1:E613-8.

21. Ravanelli M, Grammatica A, Tononcelli E, Morello R, Leali M, Battocchio S, Agazzi GM, Buglione di Monale E Bastia M, Maroldi R, Nicolai P, Farina D. Correlation between Human Papillomavirus Status and Quantitative MR Imaging Parameters including Diffusion-Weighted Imaging and Texture Features in Oropharyngeal Carcinoma. AJNR Am J Neuroradiol. 2018;39:1878-83.

22. Payabvash S, Chan A, Jabehdar Maralani P, Malhotra A. Quantitative diffusion magnetic resonance imaging for prediction of human papillomavirus status in head and neck squamous-cell carcinoma: A systematic review and meta-analysis. Neuroradiol J. 2019;32:232-40.

23. Nakahira M, Saito N, Yamaguchi H, Kuba K, Sugasawa M. Use of quantitative diffusion-weighted magnetic resonance imaging to predict human papilloma virus status in patients with oropharyngeal squamous cell carcinoma. Eur Arch Otorhinolaryngol. 2014;271:1219-25.

24. de Perrot T, Lenoir V, Domingo Ayllón M, Dulguerov N, Pusztaszeri M, Becker M. Apparent Diffusion Coefficient Histograms of Human Papillomavirus-Positive and Human Papillomavirus-Negative Head and Neck Squamous Cell Carcinoma: Assessment of Tumor Heterogeneity and Comparison with Histopathology. AJNR Am J Neuroradiol. 2017:38:2153-60.

25. van den Brekel MW, Stel HV, Castelijns JA, Nauta JJ, van der Waal I, Valk J, Meyer CJ, Snow GB. Cervical lymph node metastasis: assessment of radiologic criteria. Radiology. 1990;177:379-84.

26. Goldenberg D, Begum S, Westra WH, Khan Z, Sciubba J, Pai SI, Califano JA, Tufano RP, Koch WM. Cystic lymph node metastasis 
in patients with head and neck cancer: An HPV-associated phenomenon. Head Neck. 2008;30:898-903.

27. Morani AC, Eisbruch A, Carey TE, Hauff SJ, Walline HM, Mukherji SK. Intranodal cystic changes: a potential radiologic signature/biomarker to assess the human papillomavirus status of cases with oropharyngeal malignancies. J Comput Assist Tomogr. 2013;37:343-5.

28. Robbins KT, Clayman G, Levine PA, Medina J, Sessions R, Shaha A, Som P, Wolf GT; American Head and Neck Society; American Academy of Otolaryngology--Head and Neck Surgery. Neck dissection classification update: revisions proposed by the American Head and Neck Society and the American Academy of Otolaryngology-Head and Neck Surgery. Arch Otolaryngol Head Neck Surg. 2002;128:751-8.

29. Kolff-Gart AS, Pouwels PJ, Noij DP, Ljumanovic R, Vandecaveye V, de Keyzer F, de Bree R, de Graaf P, Knol DL, Castelijns JA. Diffusion-weighted imaging of the head and neck in healthy subjects: reproducibility of ADC values in different MRI systems and repeat sessions. AJNR Am J Neuroradiol. 2015;36:384-90.

30. Mandrekar JN. Measures of Interrater agreement. J Thorac Oncol. 2011;6:6-7.

31. Lassen P, Eriksen JG, Hamilton-Dutoit S, Tramm T, Alsner J, Overgaard J. Effect of HPV-associated p16INK4A expression on response to radiotherapy and survival in squamous cell carcinoma of the head and neck. J Clin Oncol. 2009;27:1992-8.

32. Sedghizadeh PP, Billington WD, Paxton D, Ebeed R, Mahabady S, Clark GT, Enciso R. Is p16-positive oropharyngeal squamous cell carcinoma associated with favorable prognosis? A systematic review and meta-analysis. Oral Oncol. 2016;54:15-27.

33. Chan SC, Cheng NM, Hsieh CH, Ng SH, Lin CY, Yen TC, Hsu CL, Wan HM, Liao CT, Chang KP, Wang JJ. Multiparametric imaging using 18F-FDG PET/CT heterogeneity parameters and functional MRI techniques: prognostic significance in patients with primary advanced oropharyngeal or hypopharyngeal squamous cell carcinoma treated with chemoradiotherapy. Oncotarget. 2017;8:62606-21.

34. Surov A, Gottschling S, Mawrin C, Prell J, Spielmann RP, Wienke A, Fiedler E. Diffusion-Weighted Imaging in Meningioma: Prediction of Tumor Grade and Association with Histopathological Parameters. Transl Oncol. 2015;8:517-23.

35. Sugahara T, Korogi Y, Kochi M, Ikushima I, Shigematu Y, Hirai T, Okuda T, Liang L, Ge Y, Komohara Y, Ushio Y, Takahashi M. Usefulness of diffusion-weighted MRI with echo-planar technique in the evaluation of cellularity in gliomas. J Magn Reson Imaging. 1999;9:53-60.

36. Bonello L, Preda L, Conte G, Giannitto C, Raimondi S, Ansarin M, Maffini F, Summers P, Bellomi M. Squamous cell carcinoma of the oral cavity and oropharynx: what does the apparent diffusion coefficient tell us about its histology? Acta Radiol. 2016;57:1344-51.

37. Driessen JP, Caldas-Magalhaes J, Janssen LM, Pameijer FA, Kooij N, Terhaard CH, Grolman W, Philippens ME. Diffusion-weighted MR imaging in laryngeal and hypopharyngeal carcinoma: association between apparent diffusion coefficient and histologic findings. Radiology. 2014;272:456-63.
38. Westra WH. The morphologic profile of HPV-related head and neck squamous carcinoma: implications for diagnosis, prognosis, and clinical management. Head Neck Pathol. 2012;6(Suppl 1):S48-54.

39. Kimple RJ, Smith MA, Blitzer GC, Torres AD, Martin JA, Yang RZ, Peet CR, Lorenz LD, Nickel KP, Klingelhutz AJ, Lambert PF, Harari PM. Enhanced radiation sensitivity in HPV-positive head and neck cancer. Cancer Res. 2013;73:4791-800.

40. Swartz JE, Driessen JP, van Kempen PMW, de Bree R, Janssen LM, Pameijer FA, Terhaard CHJ, Philippens MEP, Willems S. Influence of tumor and microenvironment characteristics on diffusionweighted imaging in oropharyngeal carcinoma: A pilot study. Oral Oncol. 2018;77:9-15.

41. Cantrell SC, Peck BW, Li G, Wei Q, Sturgis EM, Ginsberg LE. Differences in imaging characteristics of HPV-positive and HPVNegative oropharyngeal cancers: a blinded matched-pair analysis. AJNR Am J Neuroradiol. 2013;34:2005-9.

42. Chan MW, Yu E, Bartlett E, O'Sullivan B, Su J, Waldron J, Ringash J, Bratman SV, Chen YA, Irish J, Kim J, Gullane P, Gilbert R, Chepeha D, Perez-Ordonez B, Weinreb I, Hansen A, Tong L, Xu W, Huang SH. Morphologic and topographic radiologic features of human papillomavirus-related and -unrelated oropharyngeal carcinoma. Head Neck. 2017;39:1524-34.

43. Davis KS, Lim CM, Clump DA, Heron DE, Ohr JP, Kim S, Duvvuri U, Johnson JT, Ferris RL. Tumor volume as a predictor of survival in human papillomavirus-positive oropharyngeal cancer. Head Neck. 2016;38(Suppl 1):E1613-7.

44. Hermans R, Op de beeck K, Van den Bogaert W, Rijnders A, Staelens L, Feron M, Bellon E. The relation of CT-determined tumor parameters and local and regional outcome of tonsillar cancer after definitive radiation treatment. Int $\mathrm{J}$ Radiat Oncol Biol Phys. 2001;50:37-45.

45. Kofler B, Borena W, Dudas J, Innerhofer V, Dejaco D, Steinbichler TB, Widmann G, von Laer D, Riechelmann H. Post-Treatment HPV Surface Brushings and Risk of Relapse in Oropharyngeal Carcinoma. Cancers (Basel). 2020;12:1069.

46. Bese NS, Hendry J, Jeremic B. Effects of prolongation of overall treatment time due to unplanned interruptions during radiotherapy of different tumor sites and practical methods for compensation. Int J Radiat Oncol Biol Phys. 2007;68:654-61.

47. Russo G, Haddad R, Posner M, Machtay M. Radiation treatment breaks and ulcerative mucositis in head and neck cancer. Oncologist. 2008;13:886-98.

48. Tarnawski R, Fowler J, Skladowski K, Swierniak A, Suwiński $\mathrm{R}$, Maciejewski B, Wygoda A. How fast is repopulation of tumor cells during the treatment gap? Int J Radiat Oncol Biol Phys. 2002;54:229-36.

49. Alfaraj F, Craig T, Huang SH, O’Sullivan B, Su J, Bayley A, Bratman S, Cho J, Giuliani M, Kim J, Ringash J, Waldron J, Hansen A, de Almeida J, Perez-Ordonez B, Weinreb I, Tong L, $\mathrm{Xu} \mathrm{W}$, Hope A. Treatment outcomes in oropharynx cancer patients who did not complete planned curative radiotherapy. Oral Oncol. 2019;97:124-30. 